


\title{
MUERTE DE LENGUAS Y LENGUAS EN PELIGRO EN COSTA RICA: LA PERSPECTIVA EXOCOMUNITARIA ${ }^{1}$ DEATH OF LANGUAGES AND ENDANGERED LANGUAGES IN COSTA RICA: THE EXO-COMMUNITY PERSPECTIVE ${ }^{1}$
}

\author{
Carlos Sánchez Avendaño
}

\begin{abstract}
RESUMEN
En este artículo se analizan tres intereses fundamentales y recurrentes en el discurso de los exocomunitarios (lingüistas, antropólogos, maestros y periodistas) con respecto al fenómeno de la muerte de lenguas y las lenguas en peligro en Costa Rica: documentar y describir los idiomas ante su inminente desaparición o por motivos académicos, describir las causas y los procesos de desplazamiento lingüístico, y llamar a emprender acciones para la conservación y revitalización de los idiomas.

Palabras clave: muerte de lenguas en Costa Rica, lenguas en peligro en Costa Rica, documentación y descripción de lenguas, revitalización lingüística, causas del desplazamiento de lenguas.
\end{abstract}

\begin{abstract}
In this article, we analyze three fundamental and recurrent interests in the out-group discourse (i.e., that of linguists, anthropologists, teachers and journalists), with regard to the phenomenon of language death and language endangerment in Costa Rica: document and describe languages before their imminent loss or due to academic reasons, describe language shift causes and processes, and claim for actions to maintain and revitalize languages.

Key words: language death in Costa Rica, endangered languages in Costa Rica, language documentation and description, linguistic revitalization, causes of language shift.
\end{abstract}

\section{Introducción}

Si bien el estudio sistemático de los procesos de desplazamiento y muerte de lenguas inicia, como expone Junyent (2007), desde finales de la década de 1960 con los trabajos de Joshua Fishman, en el marco de la sociología del lenguaje, y en la década de 1970 con los trabajos de Nancy Dorian en cuanto a los procesos de obsolescencia, resulta innegable que es a partir de la década de 1990 cuando el acelerado incremento del número de lenguas en estado

Dr. Carlos Sánchez Avendaño. Universidad de Costa Rica. Profesor de la Escuela de Filología, Lingüística y Literatura. Investigador del Instituto de Investigaciones Lingüísticas. Costa Rica.

Correo electrónico: tocumarama@yahoo.es

Recepción: 18- 04- 2013

Aceptación: 31- 07- 2013 
de declinación y la situación de vulnerabilidad de gran parte del acervo lingüístico de la humanidad se convierte en foco de especial atención y preocupación, no solo de los lingüistas, sino también de instituciones supranacionales, instancias gubernamentales, medios de comunicación masivos y miembros de comunidades etnolingüísticas cuyos idiomas vernáculos se encuentran en peligro (Grinevald y Costa, 2010; Heller y Duchêne, 2007).

Dado que la situación sociolingüística de Costa Rica no constituye ninguna excepción a la tendencia mundial de pérdida acelerada de la diversidad idiomática, a partir de la década de 1980 aparecerán los estudios académicos centrados en describir la vitalidad estructural y sociolingüística de las lenguas indocostarricenses y el inglés criollo de la provincia de Limón. Asimismo, debido a que los discursos acerca de las lenguas en peligro se han internacionalizado (Cameron, 2007), la prensa costarricense se ha interesado en los últimos años por publicar noticias acerca del fenómeno en el nivel mundial y su manifestación en el nivel local. Así se muestra, por ejemplo, en el artículo "Nueve lenguas de Costa Rica están en peligro de extinción":

\footnotetext{
Nueve lenguas de Costa Rica están en vías de extinción, según la edición del 2009 del Atlas de las Lenguas en Peligro, presentado recientemente por la Organización de las Naciones Unidas para la Educación, la Ciencia y la Cultura (Unesco).

El organismo determinó que la guaymí, bribri, cabécar, criolla limonense, ngäbere, guatuso, boruca, teribe y chorotega se encuentran, de una manera u otra, en peligro de desaparición. (La Nación, 27 de mayo de 2009)
}

Sin embargo, cabe destacar que, en Costa Rica, el interés académico por la desaparición de los idiomas autóctonos no es reciente. Por el contrario, ya desde finales del siglo XIX, desde los trabajos pioneros de documentación y descripción de las lenguas amerindias, se vienen enfatizando las causas, síntomas y desarrollo de este fenómeno, como veremos más adelante. Esto significa que existe conciencia sobre la muerte de lenguas desde los estudios pioneros, los cuales no responden ni a la preocupación reciente ni al discurso internacionalizado acerca de las lenguas en peligro.

Por ende, en vista de que estamos ante una larga tradición discursiva que se ha ocupado, al menos tangencialmente, de la muerte de las lenguas autóctonas de Costa Rica y dada la variedad de discursos al respecto $-\mathrm{y}$ de instancias emisoras de tales discursos-, el análisis de las perspectivas con las que se ha asumido el problema de la muerte de idiomas y de las lenguas en peligro en Costa Rica nos sirve para formarnos una idea somera acerca de la diversidad ideológica involucrada en el tratamiento del tema.

Por este motivo, en el presente trabajo, examinamos la perspectiva y los intereses que aparecen en el discurso sobre el desplazamiento y la muerte de las lenguas minoritarias de Costa Rica producido por individuos externos a las comunidades etnolingüísticas cuyas lenguas vernáculas se encuentran en peligro. En un trabajo futuro, pretendemos ocuparnos de analizar la perspectiva de los propios miembros de las comunidades etnolingüísticas con respecto a dichos fenómenos. En este artículo nos hemos de referir a estas dos posiciones en términos de "la perspectiva exocomunitaria" frente a "la perspectiva endocomunitaria".

La perspectiva exocomunitaria corresponde a aquella asumida y expuesta por intelectuales extranjeros y nacionales, antropólogos, lingüistas, maestros y periodistas, quienes no pertenecen a ninguno de los grupos cuyas lenguas vernáculas están en peligro de desaparecer o están atravesando o han atravesado por un proceso de desplazamiento. De la producción y de los discursos de estos individuos examinamos en particular dos aspectos: la forma en que 
se ha procedido dentro de cada interés (metodologías, estrategias, marcos teóricos, resultados, publicaciones), y los comentarios, explicaciones y justificaciones explícitas relacionados con el trabajo relativo a estos intereses y modos de proceder.

\section{Las lenguas de Costa Rica y el interés por su vitalidad}

En los textos de la época colonial, se menciona la existencia de una gran diversidad de pueblos autóctonos en lo que actualmente se considera territorio costarricense y zonas aledañas a este. Es difícil determinar con certeza cuáles de ellos constituían grupos etnolingüísticos diferenciados, pero Constenla-Umaña e Ibarra-Rojas (2009) plantean que la conformación lingüística de Costa Rica en el siglo XVI incluía ocho idiomas de la familia chibcha (boruca, bribri, cabécar, chánguena, guatuso, huetar, rama, teribe) y dos mesoamericanos (nahua, chorotega). Según estos autores, otros pueblos frecuentemente mencionados en las fuentes no habrían hablado lenguas distintas a las citadas. Así, los corobicíes posiblemente habrían hablado rama; los suerres, cabécar; y los quepos y cotos, boruca.

Aparte del bribri, el cabécar, el teribe-térraba, el guatuso (malecu) y el boruca (brunca), lenguas de las que se recogieron materiales de diversa extensión desde finales del siglo XIX e inicios del XX (Gabb, 1875; Thiel, 1882; Pittier, 1897, 1898, 1941; Pittier y Gagini, 1892; Gagini, 1917; Lehmann, 1920) y, con mayor profusión, a partir de la segunda mitad del siglo XX (Arroyo, 1966; Porras-Ledesma, 1959; Constenla-Umaña, 1975) -y cuyas respectivas comunidades de hablantes se han mantenido o se conciben como entidades étnicas diferenciadas hasta nuestros días-, de los idiomas de los demás pueblos mencionados en las fuentes coloniales solo quedaron, en el mejor de los casos, algunos antropónimos, palabras aisladas, oraciones sueltas y algún sustrato léxico en las variedades del español costarricense (Constenla-Umaña, 1984, 1994; Quesada-Pacheco, 1996a, 2006; Quirós-Rodríguez, 1987, 2002).

Durante la segunda mitad del siglo XIX, emigra a la costa atlántica de Costa Rica un importante contingente de afrodescendientes originarios de las islas del Caribe, sobre todo de Jamaica (Herzfeld, 2002). Con ellos llega al país una variedad criolla de inglés (denominada de diversas maneras: "mekatelyu" o "mekaytelyuw", "patuá" -del francés "patois"-, "inglés limonense", "broken English" o simplemente "inglés"). De esta forma, la situación sociolingüística de la región sudeste del país se transformará, pues una nueva población con una nueva lengua entrará en contacto con los grupos indígenas que sobrevivieron como pueblos diferenciados hasta esa época.

Posteriormente, a partir de la segunda mitad del siglo XX, se asientan en el Pacífico sur del país algunos núcleos de noves (ngäbe, guaimíes, moves) y bugleres (bocotás) que emigraron en conjunto desde Chiriquí, Panamá (Laurencich, 1974). Estas dos poblaciones con sus propias lenguas pasarán a formar parte de los intereses investigativos de los académicos costarricenses a partir de la década de 1970.

Por último, habría que mencionar la lengua de señas costarricense (lesco ${ }^{2}$ ), idioma con hablantes en todo el territorio, pero con una concentración evidente en el Valle Central (Woodward, 1991; Retana-Castro, 2011), del que se ha dicho que existen dos variedades muy diferenciadas de acuerdo con el factor generacional, al punto de que Woodward (1992) se refiere a ellas como la variedad original (OLESCO) y la variedad nueva (NLESCO).

La actitud frente a la diversidad lingüística y el interés por la vitalidad o el desplazamiento de los idiomas endógenos ha variado a lo largo de la historia del país. En el momento de la conquista española del territorio y durante los siglos XVI y XVII, debido 
al afán por subyugar a las poblaciones autóctonas y someterlas a su servicio, probablemente predominó la consternación de los conquistadores por los problemas logísticos que ocasionaba la diversidad de idiomas (Ibarra-Rojas, 1990).

Según Constenla-Umaña (2004), a inicios del siglo XVIII, debido al muy probable avanzado desplazamiento del huetar -idioma que aparentemente funcionaba como lingua franca regional-, el interés por aprender y describir las lenguas locales, con fines evangelizadores, se habría incrementado. Posteriormente, en el siglo XIX, la ideología de que Costa Rica contaba con una población de origen predominantemente europeo se consolidó y ya a finales de este siglo la creencia de que los indígenas que sobrevivieron al sistema de explotación colonial estaban por desaparecer toma fuerza de la mano de diversos intelectuales costarricenses y extranjeros (Boza-Villareal, 2005; Molina-Jiménez, 2008).

Evidentemente, la especificidad lingüística de esos grupos -considerados atrasados, primitivos y salvajes, de acuerdo con los cánones ideológicos de la época, muchos de los cuales lamentablemente siguen aún vigentes- importará poco a los hispanocostarricenses, así que la labor de descripción recaerá en varios intelectuales europeos y estadounidenses, individuos con formación e intereses diversos (botánica, geología, arqueología, etnología, lingüística), caracterizados por tal pasión científica y coleccionista que procurarán inventariar todas las riquezas naturales y antropológicas a las que tuvieron acceso, incluyendo las lenguas de las poblaciones indígenas. Entre estos intelectuales sobresaldrán las figuras de William Gabb, Bernardo Augusto Thiel, Henri Pittier y Walter Lehmann.

Con ellos, empieza el interés por levantar listas relativamente extensas de vocabulario y describir la fonología y la gramática de las lenguas indocostarricenses, así como por recoger muestras de textos orales. Constenla-Umaña (2004) considera que la mayor parte de este trabajo descriptivo es deficiente en cuanto a la precisión de los datos recogidos. No obstante, cabe destacar que son estos extranjeros quienes nos dejarán las primeras noticias detalladas de la situación sociolingüística del país para finales del siglo XIX e inicios del XX, al plasmar sus impresiones acerca de la vitalidad de los idiomas de las poblaciones indígenas.

A estos intelectuales extranjeros los seguirán los intelectuales nacionales del siglo XX: Carlos Gagini (1917), quien de todas formas ya había colaborado con Henri Pittier en una publicación sobre el térraba (Pittier y Gagini, 1892), y Víctor Manuel Arroyo (1966). Además de levantar listados de vocabularios, ambos se ocuparán de llevar a cabo esbozos gramaticales y fonológicos, y de paso nos legarán algunas observaciones sobre la vitalidad de los idiomas. Les seguirán los trabajos pioneros de Porras-Ledesma (1959) y Constenla-Umaña (1975), en los cuales no solo se describirá la estructura lingüística, sino que además se comentará con algún detalle la situación sociolingüística del grupo investigado (los malecus, en ambos casos).

A dichos trabajos se sumará, a partir de la década de 1970, una gran cantidad de artículos, libros y tesis de grado y de posgrado sobre las lenguas indocostarricenses, el inglés limonense y, en mucha menor medida, la lengua de señas costarricense, llevados a cabo desde diversas perspectivas teórico-metodológicas dentro de la ciencia lingüística, pero en los que predominan los estudios de corte estructuralista, generativista y, más recientemente, funcionalista (Constenla-Umaña, 2004, 2011b; Sánchez-Avendaño, 2013). Eso sí, será muy variable la atención prestada a describir, o al menos mencionar tangencialmente, el estado de vitalidad de las lenguas estudiadas y la situación sociolingüística de las respectivas comunidades. De hecho, en la gran mayoría de las publicaciones lingüísticas estos temas ni siquiera se tratan, mientras que en las que sí lo hacen apenas se esboza la situación o se menciona de modo marginal. 
Será a partir de la tesis de Portilla-Chaves (1985) -cuyos principales resultados aparecerán en forma de artículo un año después (Portilla, 1986)- cuando comenzarán a publicarse estudios cuyo centro de interés será, total o parcialmente, el análisis sistemático de la vitalidad (estructural y sociolingüística) de las lenguas minoritarias de Costa Rica y su proceso de desplazamiento: Castro (2008), Constenla-Umaña (1988), Herzfeld (2002, 2011), Murillo-Miranda (2008), Quesada (2000, 2001-2002, 2008a), Quesada Pacheco (1996a, 1999-2000, 2008a, 2008b, 2009), Sánchez Avendaño (2009), Spence (1997, 2001), Umaña-Aguiar (1991), Winkler (2000), Zimmer (2011).

Asimismo, verán la luz estudios panorámicos sobre la situación de todas las lenguas indocostarricenses o un conjunto de estas (Constenla-Umaña, 2011b, 2011a; Margery-Peña, 1993; Quesada-Pacheco, 2008a, 2008b), la familia chibcha en su totalidad (Quesada, 2008b) o algunas de sus subagrupaciones (Quesada-Pacheco, 2008b, 2009), la historia de los idiomas indígenas de algunas regiones (Constenla-Umaña, 1994) y las lenguas minoritarias costarricenses en general, incluyendo, por consiguiente, el criollo limonense y el lesco (Sánchez-Avendaño, 2009, 2013).

Por su parte, en las publicaciones antropológicas que exponen la historia y situación actual de los pueblos indocostarricenses (Bozzoli de Wille, 1969, 1986; Guevara-Berger y Chacón-Castro, 1992; Guevara-Berger y Bozzoli-Vargas, 2002) -así como en otros textos elaborados por instituciones o grupos preocupados por la realidad de los pueblos originarios del país (v.gr. FUNCOOPA, 1997)-, casi siempre se comenta, con mayor o menor detalle, la situación sociolingüística de estos y el estado de conservación de sus lenguas vernáculas, si bien pocas veces se profundiza en el tema, pues el interés radica en señalar la pérdida de los idiomas autóctonos como muestra del avanzado proceso de aculturación. Así por ejemplo, de acuerdo con Guevara-Berger y Chacón-Castro (1992):

La pérdida de valores autóctonos se dio en diversos grados en la región [de Buenos Aires de Puntarenas]. Los talamanqueños (Bribris y Cabécares) conservaron muchas de sus tradiciones: idioma, festividades, métodos de trabajo, chichadas, y muchas otras. Borucas y Térrabas en cambio han sufrido la aculturación al grado de haber llegado casi a perder sus respectivas lenguas. (1992, p. 113)

En resumen, según lo anotado, preliminarmente -y para efectos de la presente exposición-, podemos distinguir tres etapas o épocas en la lingüística costarricense ocupada de las lenguas minoritarias del país:

a. Finales del siglo XIX y primeros años del siglo XX: trabajo empírico de documentación y descripción llevado a cabo por académicos extranjeros.

b. Primera mitad del siglo XX: trabajo de documentación y descripción llevado a cabo, sobre todo, por académicos costarricenses, aunque con la participación de extranjeros, con ya algún sustento científico, pero sin basarse teórica o metodológicamente aún en la lingüística de modo sistemático.

c. Segunda mitad del siglo XX y primeros años del siglo XXI: trabajo de documentación y descripción llevado a cabo, principalmente, por académicos costarricenses con formación en lingüística.

\section{Los intereses con respecto a la muerte de lenguas y las lenguas en peligro en Costa Rica en los discursos exocomunitarios}

A continuación examinaremos los principales intereses y procederes, con respecto a las lenguas en peligro en Costa Rica, que aparecen tanto implícitos como explícitos en publicaciones cuyo autor o emisor es un individuo exocomunitario ${ }^{3}$. Básicamente, identificamos y tratamos con 
detalle tres intereses fundamentales y recurrentes en la historia de la lingüística en Costa Rica concerniente a las lenguas minoritarias del país. No nos ocupamos de lo que podría denominarse "intereses marginales" en el discurso exocomunitario, pues se trata de alusiones esporádicas o que se explicitan únicamente en un autor, como por ejemplo la finalidad de facilitar la comunicación interétnica que señala Thiel (1882) en su libro de recopilación de listados léxicos en varios idiomas:

\begin{abstract}
Estos apuntes hice en los diferentes viajes que en el curso del año de 1881 y del presente, emprendí á los territorios de la Talamanca y Guatuso, y á los pueblos de Térraba y Boruca. Mi intención era no publicarlos sino hasta completarlos y arreglar la gramática de estas lenguas. Mas, cediendo á las instancias de varias personas, y viendo la necesidad de facilitar el comercio y trato con los indios, me he resuelto á publicarlos en el actual estado. (Thiel, 1882, p. III) ${ }^{4}$
\end{abstract}

\title{
3.1. Primer interés: Documentar y describir las lenguas ante su inminente desaparición o por motivación académica
}

Desde Gabb (1875) -el primero en realizar un trabajo descriptivo acerca de los idiomas de la población nativa de Costa Rica-, el tema de la muerte de lenguas y las lenguas en peligro de desaparecer ha estado presente en el discurso exocomunitario. Asimismo, el interés explícito por recoger muestras de las lenguas y del arte verbal de los respectivos pueblos, antes de que estos desaparezcan, se remonta a las primeras publicaciones (Pittier y Gagini, 1892; Lehmann, 1920; Gagini, 1917; Pittier, 1941; Arroyo, 1966).

En el caso de Gabb (1875), este se refiere constantemente a las lenguas que ya habían desaparecido para el momento de su arribo al país y a la situación sociolinguiística de los pueblos existentes en la segunda mitad del siglo XIX; sin embargo, no parece mostrarse preocupado por la extinción de los idiomas per se, sino que se limita a consignar los datos de los que disponía para su época acerca de la desaparición de los grupos indígenas y sus lenguas vernáculas:

\footnotetext{
Una fatalidad extraña parece pesar sobre estos indios istmeños. Aun cuando no se aproximen al contacto de las deletéreas influencias de la civilización, se ve palpablemente que las tribus disminuyen. Ha menos de dos siglos que la población de Talamanca, nombre con que en Costa-Rica se designa esa provincia del Sudeste, se contaba por millares; hoy día apenas se hallarán 1200 almas. La tribu Shelaba ha desaparecido; los Changuinas están á punto de ser exterminados; los Tiribíes cuenta una población de 103 almas; y Lyon me dice que la población de los Cabécares del Coén se ha disminuido en más de la mitad, en los últimos diez y siete años, mientras que la disminución de los Bribris es apenas menos rápida. (Gabb, 1883, p. 333) ${ }^{5}$
}

Con Gabb comienza la era de los exploradores naturalistas extranjeros, interesados por inventariar todo lo que pudieran, desde muestras botánicas y geológicas hasta topónimos y vocabularios. En este sentido, en el trabajo llevado a cabo en Costa Rica se revela claramente la tendencia, descrita por Mercier (1976), propia de los intelectuales alemanes y estadounidenses particularmente los naturalistas y geógrafos- de cultivar la antropología sociocultural y realizar trabajo de campo de índole etnológica, afín con la empresa decimonónica de aprovechar los viajes con el propósito de recoger datos etnológicos, los cuales solían enviarse a los museos etnográficos creados a partir de este mismo siglo, con el propósito de resguardar acopios de muestras de la cultura material de diversos pueblos.

La caracterización de Mercier (1976) relativa a los investigadores de mediados del siglo XIX describe perfectamente el perfil de los lingüistas-antropólogos empíricos que se dedicaron al estudio de las lenguas indígenas de Costa Rica en esta época:

Toda esta generación de antropólogos poseía una curiosidad insaciable y una erudición sorprendente [...]. Se ha dicho que varios de ellos -y también de la generación siguiente-dominaban el campo completo de la antropología en su sentido más amplio [...]. Estos investigadores crearon una disciplina -sin atribuirse a 
sí mismos [...] el título de antropólogo-y, por supuesto, no habían recibido formación como tales, sino que eran espíritus curiosos que continuaron sirviendo a su antigua disciplina al mismo tiempo que construían una nueva, y lo mismo sucedería todavía, en parte, con la generación siguiente. (Mercier, 1976, p. 40)

Por este motivo, pese a que, de acuerdo con los parámetros ideológicos de la época, la aculturación (hispanización) de los grupos indocostarricenses se valora como acercamiento a la "civilización", se cree en la necesidad de documentar las costumbres y componentes de las culturas tradicionales de estos pueblos, ante su progresivo desplazamiento. Así, este proceso, si bien se toma como signo de evolución cultural (paso de un estado "salvaje" a un estado "civilizado"), también se concibe como pérdida de información etnológica que se considera importante registrar.

Esta preocupación por inventariar lo que se supone ha de desaparecer pronto parece ser el móvil desde las investigaciones de finales del siglo XIX hasta las de la década de 1970. Por ello, son constantes desde el trabajo fundacional de Gabb las referencias a la vitalidad cultural y lingüística de los pueblos con los que el investigador tenía contacto:

[T]anto los Térrabas, como sus vecinos los Bruncas, ó como los llaman los españoles, los Borucas, viven en una ó dos pequeñas aldeas y están bajo la completa sumisión de sacerdotes misioneros, así en lo eclesiástico como en lo municipal, y van perdiendo rápidamente la lengua y sus costumbres salvajes y se están aproximando á la condición civilizada de las aldeas de Pacaca, Co, Quircó, \&., en Costa-Rica, donde los indios hablan solamente castellano, y hasta han perdido las tradiciones de su antiguo modo de ser. (Gabb, 1883, p. 388)

Un buen ejemplo de la pasión coleccionista y del interés por registrar los últimos remanentes de lenguas casi desaparecidas se encuentra en Walter Lehmann, quien, en una carta de 1909 dirigida a Globus para relatar sus trabajos en América Central, escribe:

\footnotetext{
En Costa Rica pude también estudiar a los indios primitivos y hacer una bonita colección etnográfica de los indios chirripós, cuidadosamente planeada, la cual asimismo está en Berlín desde hace mucho tiempo. Tengo extensos vocabularios, gramáticas y textos de las lenguas de Talamanca (bribri, chirripó y del Río Lari).

En Nicaragua he continuado con estos estudios, los cuales hasta ahora cobran cohesión.

Con este propósito he realizado largos viajes para salvar lenguas, tradiciones, costumbres, etc., todavía existentes, en vista de que están en peligro de extinción.

En Subtiaba, cerca de León, me encontré con una señora de 84 años que todavía hablaba subtiaba. Pude recoger un extenso vocabulario junto con apuntes gramaticales de esta curiosa lengua aislada. [...] En la región de Masaya estuve buscando durante un mes la lengua chorotega, pero es extinta. Solamente pude salvar algunas palabras. (Lehmann, 1909, compilado en Quesada-Pacheco, 2001, pp. 525-527)
}

Así, el interés etnológico es principalmente de tipo coleccionista y descriptivo, y la noción de documentación que se maneja consiste en elaborar una especie de museística idiomática: recoger muestras de las lenguas -sobre todo palabras-, sin mayores pretensiones que el acopio y acumulación de datos. Por lo demás, muchas veces se suelen tratar los vocablos simplemente como significantes distintos para codificar los mismos significados, lo que explica que los listados léxicos se consignen como meros equivalentes semánticos lengua indígenaespañol y viceversa, sin matizaciones y sin ejemplos sobre el uso.

En otras palabras, no se toma en cuenta el análisis de la experiencia en la expresión linguiística ni las funciones particulares de los signos en la comunicación ni la organización idiosincrática de los idiomas, aspectos que, como señalaba hace años Martinet (1962), constituyen lo diferencial en las lenguas. Por el contrario, la descripción se concentra en recoger las distintas sustancias fónicas de las unidades (las secuencias fonológicas que configuran los significantes), con el supuesto de que el significado y la función son básicamente los mismas entre las diversas lenguas ${ }^{6}$. En gran medida, este proceder corresponde todavía a lo que Haviland (2006) 
denomina la tradición lexicográfica "colonial”, en la cual el inventario léxico no está destinado a los hablantes del idioma documentado, sino que responde a un interés coleccionista.

En los discursos en los que aparece este primer interés, se explicita y enfatiza la relevancia de llevar a cabo registros de idiomas condenados a desaparecer como algo valioso per se, como se muestra en el prólogo de Juvenal Valerio Rodríguez, director del Museo Nacional en 1937, a un texto de Pittier sobre los bribris:

"El Doctor Pittier, que tanto trabajó por establecer en nuestro país las bases para el estudio de la Etnología
y la Linguística, guarda inéditos sus extensos vocabularios del cabécar y del brunka, junto con los
revisados y aumentados del bribrí y del térraba, y se perderán sin duda -agrega Pittier-, lo que es lástima,
por la importancia que hay en conservar esos "records" de idiomas que pronto quedarán sólo como
memoria". (Pittier, 1938, p. 10)

Además, en la perspectiva de estos primeros autores, las lenguas se corrompen o pierden su pureza y la incorporación de préstamos de otros idiomas evidencia la degeneración lingüística. De este modo, en los intelectuales de este período (tales como Pittier y Gagini, 1892; Pittier, 1941; Gagini, 1917 y Arroyo, 1966), el préstamo no se toma como evidencia de contacto, sino como signo de pérdida de pureza y, sobre todo, como augurio de la desaparición de los idiomas indígenas. Así se revela en las siguientes palabras de Gagini: "De nuestros dialectos indígenas este [el brunca o boruca] es sin duda el más mezclado con voces castellanas, y por consiguiente el más expuesto a desaparecer primero" (1917, p. 33).

El discurso de la decadencia lingüística como signo de pronta extinción del idioma perdurará en las descripciones hasta bien avanzado el siglo XX. En Arroyo (1966), la última publicación que podría considerarse "pre-científica" -en el sentido de que después de ella los estudios que aparecerán se ceñirán a teorías y metodologías de distintas corrientes de la lingüística como disciplina académica-, encontraremos el eslabón final de esta primera preocupación con respecto a las lenguas minoritarias de Costa Rica: "El habla actual de los brunkas presenta numerosísimas palabras castellanas o modificaciones de ellas que, ingresando constantemente a la lengua aborigen, contribuyen a su pronta desaparición. Son innumerables las voces del vocabulario de Pittier que se han perdido" (Arroyo, 1966, p. 24).

Pese a lo anotado, la incitación a intervenir en el proceso de desplazamiento y extinción de las lenguas indígenas no está ausente en esta primera etapa. No obstante, para estos autores, el eje de la argumentación a favor de intervenir se refiere a la necesidad de documentar los idiomas, debido a una motivación científica etnológica, ante lo que ellos consideran la inminente desaparición de estos. Los actores a los que se invita a llevar a cabo las descripciones e inventarios son el gobierno, como promotor de investigaciones, y los lingüistas, como expertos en documentación de datos idiomáticos, como se aprecia en los siguientes textos:

\footnotetext{
Mis empeños para averiguar si entre los restos de la escasísima población indígena de Nicoya se conserva aún la lengua chorotega, no tuvieron éxito, por desgracia [...].

No dudo de que en Nicaragua, donde es mayor el número de los indios que en Guanacaste y Nicoya, se encuentren aún algunas aldeas chorotegas cuyos habitantes hayan conservado su antiguo idioma. Sería muy meritorio que viajeros provistos de los conocimientos lingüísticos necesarios, coleccionaran los residuos de esta lengua antes de que desaparezca completamente; pues de lo contrario, nuestros conocimientos de ella quedarían reducidos a sólo nombres de lugares y a la mezquina lista de algunas palabras. (von Frantzius, 1925b, p. 226)
}

¡Cuántos problemas interesantes presentan la etnología, la lingüística, arqueología, geografía e historia costarricenses! [...]

Hay mucho por hacer todavía y toca al Gobierno promover esas investigaciones antes que las tribus indígenas desaparezcan para siempre y el daño sea entonces irremediable. (Gagini, 1917, p. 4) 
Pasada esta primera etapa en la cual lo que importaba básicamente era elaborar un inventario etnológico, el interés documentalista en torno a las lenguas en peligro continuará presente en las publicaciones de académicos costarricenses que versan sobre la estructura de las lenguas. La mayoría de las veces, los trabajos ofrecen una descripción detallada de la fonología o la gramática (o algún aspecto de estas) de las lenguas, desde diversas perspectivas teóricas (Sánchez-Avendaño, 2013), sin hacer alusión a la "utilidad" o motivación de dicha labor.

De ello se puede inferir que lo que interesa es, sobre todo, la índole académica del trabajo: llevar a cabo una descripción sistemática de algún componente o de la estructura de la lengua de modo holístico, la aplicación de alguna teoría o marco metodológico, la contrastación de hipótesis y datos lingüísticos provenientes de idiomas no considerados en su formulación, y el cúmulo de datos para futuros trabajos lingüísticos. Más recientemente, puede ser que se declare la importancia de documentar el patrimonio lingüístico o la diversidad idiomática del país o que se aluda al posible empleo de la descripción en la elaboración de materiales didácticos y proyectos de revitalización, como apreciaremos adelante.

La grabación en la lengua original, transcripción, traducción al español y publicación de muestras representativas del arte verbal y la tradición oral de los pueblos indocostarricenses ha sido desde antiguo otra de las preocupaciones de los lingüistas costarricenses, si bien no es común que los autores enuncien con explicitud las razones por las cuales han emprendido este tipo de labor.

Aun así, se encuentran breves alusiones a las posibles funciones que los libros podrían cumplir: rescatar el arte verbal antes de que desaparezca por completo (motivo que, por ejemplo, Quesada-Pacheco (1996b) explicita en su libro recopilatorio de textos bruncas), poner a disposición de los investigadores (lingüistas, antropólogos, mitólogos, folclorólogos, etc.) materiales para el estudio de las lenguas y de las literaturas tradicionales, difundir datos de la cultura de los pueblos indígenas para el conocimiento de los hispanocostarricenses, ofrecer lecturas para las escuelas indígenas (con miras a la alfabetización o el aprendizaje del idioma), y fomentar el aprecio de la tradición oral entre los miembros de los propios grupos.

A modo de ejemplo, dos de estos propósitos son señalados por Constenla-Umaña en la primera recopilación sistemática y con tratamiento lingüístico (transcripción en la lengua original, así como traducción literal especializada o morfemática y traducción libre al español) de textos tradicionales en una lengua indocostarricense (el brunca o boruca):

\footnotetext{
[O]pinaba que la misma [la obra] vendría a cumplir por lo menos dos funciones importantes: reunir en forma bilingüe cierta cantidad de textos para ponerlos a la disposición de quienes por diversos motivos desearan estudiar la literatura oral boruca y dotar a los niños borucas de lecturas que los estimularan al alfabetizárselos en su propia lengua. (Constenla-Umaña y Maroto, 1979, p. 7)
}

A pesar de que la práctica usual desde este primer trabajo de Constenla-Umaña ha sido la publicación de recopilaciones de arte verbal o muestras discursivas de los idiomas malecu (guatuso), bribri, brunca (boruca), cabécar, nove (guaymí) y buglere (bocotá) con tratamiento especializado (lo que incluye la cuidadosa transcripción de los textos originales en ortografía práctica, con traducción literal morfemática y traducción libre al español, además de notas etnográficas y explicativas ${ }^{8}$, pocas veces los autores han justificado este proceder, lo cual quizás haya llevado a que se perciba a veces como minucias técnicas sin importancia para los miembros de las comunidades. El único caso claro en el que se explica la razón de recopilar los textos en la lengua original, así como de incluir la traducción morfemática, se encuentra en la introducción de Jara a su libro de narraciones bribris: 


\begin{abstract}
Desgraciadamente y a pesar de lo loable del esfuerzo por recopilar narraciones indígenas, la omisión de los textos originales significa una carencia importante en esta labor y resta credibilidad al material recopilado y traducido. Muchos lingüistas creemos que solo representa un cincuenta por ciento de su valor una narración de cuya versión original no se dispone. Por otra parte, tampoco resulta un trabajo completo la presentación de un texto original, útil solo para los hablantes alfabetos de la lengua, por un lado, y de una traducción libre en español cuya fidelidad el lector no tiene por qué dar por garantizada, por el otro. Por esta razón, considero imprescindible que la bibliografía de la narrativa bribri, si bien notablemente vasta en sus versiones españolas, sea complementada con textos completos -texto original, traducción palabra por palabra, versión libre y notas explicativas-, de manera que manifieste sus tres dimensiones a un tiempo: folclórica, etnolingüística y literaria. La versión en español dará cuenta de los contenidos o el aspecto semántico de las narraciones en cuanto a historia, tradiciones, creencias, mitos, religión, etc. La traducción palabra por palabra le dará al lector tanto bribri como no bribri la representación fidedigna de las estructuras lingüísticas y con ellos una mayor credibilidad a la versión libre, y el texto original preservará esta lengua, de por sí en peligro de extinción, y con ello la cultura bribri en general. (Jara, 1993, p. 14)
\end{abstract}

Asimismo, en una obra relativa a textos cosmogónicos del pueblo malecu, Constenla se refiere ampliamente al propósito de difundir y promover el conocimiento sobre el patrimonio conformado por la literatura oral indígena como una de las motivaciones principales para este tipo de publicaciones, tanto entre los hispanocostarricenses como entre las nuevas generaciones de endocomunitarios. De nuevo, la explicitación de este tipo de razones no ha sido habitual:

\begin{abstract}
Desde que entré en contacto con los guatusos me fascinaron su cultura tradicional y los textos producidos como parte de ésta. Conforme me fui familiarizando con ellos pensé que era conveniente que los costarricenses pudieran llegar a conocer y a disfrutar, como lo había podido hacer yo, estas bellas creaciones de una de las etnias que forman parte de la nación, y tuvieran en ello un motivo de orgullo. Poco conscientes están la mayor parte de mis compatriotas de la inmensa riqueza de la tradición oral de nuestros distintos grupos étnicos. Las etnias indígenas entre las que se mantiene fuerte la tradición oral nativa (guatusos, bribris, cabécares, moveres o guaimíes, y bocotaes) tienen, cada una, una literatura distinta que incluye en todos los casos, para mencionar sólo lo narrativo, ciclos de textos perfectamente comparables a los que componen, por ejemplo, el Popol Vuh. [...]. Desde este punto de vista, quise poner a la disposición de los costarricenses una de las varias epopeyas indígenas que, por lo general, desconocen que existan en el país.

Por otra parte, no menos importante ha sido un propósito relativo a los guatusos mismos. Hasta el momento no se ha publicado ninguna obra que recoja una muestra, aunque sea modesta, de la riqueza de sus tradiciones, desconocidas por muchos de sus jóvenes. Deseo que este trabajo les permita instruirse al respecto y admirar una pequeña parte de lo que es su más íntima herencia [...]. (Constenla-Umaña, Castro y Blanco, 1993, p. 43)
\end{abstract}

En suma, entonces, el interés documentalista y descriptivo, iniciado en Costa Rica por académicos extranjeros desde finales del siglo XIX y llevado a cabo casi siempre de un modo empírico (es decir, sin sustento en los aportes teóricos y metodológicos de la ciencia linguiística), se profesionalizó a partir de la segunda mitad del siglo XX y fue continuado desde entonces por lingüistas costarricenses.

En cuanto a las motivaciones subyacentes a esta labor, cabe destacar que, en un inicio, parece tratarse de la documentación per se; esto es, la preocupación principal consistía en recopilar y guardar para la posteridad muestras (especialmente léxicas) de idiomas obsolescentes, en declinación o que se suponían próximos a desaparecer, simplemente por un interés coleccionista o museístico. Luego, ya en el período de trabajo lingüístico profesional y sobre todo a partir de la década de 1990, algunos autores explicitarán lo que, a su entender, podrían ser aplicaciones y proyecciones del trabajo descriptivo y de documentación de muestras discursivas, sobre todo en lo concerniente a su utilidad como material didáctico (o para la elaboración de materiales didácticos) y a su valor literario y antropológico tanto para los miembros de las comunidades implicadas como para los hispanocostarricenses. 
Aunque la producción académica de documentación y descripción de las lenguas de Costa Rica y sus artes verbales ha sido abundante (Sánchez-Avendaño, 2013) e incluso podría calificarse de sobresaliente en el contexto centroamericano (Constenla-Umaña, 2004, 2011b), son escasas las explicaciones o justificaciones explícitas en las obras publicadas en torno a esta labor. Empero, implícitamente se puede apreciar que el propósito fundamental ha sido de naturaleza académicolingüística: se documenta y se describe, principalmente, para los lingüistas y otros académicos, para el "progreso" de la ciencia linguiística, para la verificación y aplicación de teorías.

Aun así, sería injusto no reconocer que, cada vez con más fuerza, se hace patente el interés por documentar para el provecho directo e inmediato de las comunidades de hablantes de las respectivas lenguas, como veremos en el apartado 3.2.

\subsection{Segundo interés: Describir las causas y los procesos de desplazamiento de las lenguas vernáculas}

Como ya vimos, desde finales del siglo XIX, cuando comienza la labor descriptiva acerca de las lenguas indocostarricenses, los autores se han interesado particularmente por indicar que los pueblos indígenas se hallaban en evidente decrecimiento y se encaminaban a la desaparición como grupos sociales diferenciados. En algunos casos, también se señalaban las razones por las que esto estaba ocurriendo, al estilo de lo comentado por Pittier (1904) en un artículo sobre los térrabas. En este, el naturalista suizo expone su convicción de que los indígenas costarricenses desaparecerían irremediablemente debido a la pérdida de sus territorios y medios de sobrevivencia, además de por aferrarse a su economía de subsistencia. En su opinión, al examinar estos hechos, "uno se convence aún más de que los aborígenes de Costa Rica llegarán a extinguirse en corto tiempo" (compilado en Quesada-Pacheco, 2001, p. 466).9

Así, algunos autores de la primera época se interesaron por señalar someramente las causas de la desaparición o de la conservación de los grupos indígenas y, por extensión, de sus lenguas vernáculas. Básicamente, estos intelectuales destacarán el papel fundamental del aislamiento, con respecto a los núcleos habitacionales de hispanos ("blancos"), como factor determinante en el proceso de mantenimiento o desplazamiento de los idiomas endémicos, al estilo de lo que señala Gagini en el esbozo gramatical que figura en el texto sobre el térraba publicado por él y Pittier y, años más tarde, también en su libro sobre las pueblos indígenas de Costa Rica:

\footnotetext{
Los idiomas autóctonos del Nuevo Mundo se han ido modificando rápidamente al contacto de los europeos, á extremo de que algunos no son ya sino algarabías ó mezclas informes de palabras de unos y otros. Esto no puede en rigor aplicarse á las lenguas del sur de Costa Rica, que se han conservado bastante puras á causa del aislamiento en que viven dichas tribus y de la consíderable distancia que separa su territorio de las poblaciones blancas. (Pittier y Gagini, 1892, p. 11)

Debido a las dificultades de comunicación entre varias comarcas del país, ya por lo fragoso del suelo en el interior, o los pantanos en las costas, y al relativo aislamiento en que vivió Costa Rica antes de abrirse paso hacia el Atlántico, varias tribus han podido subsistir con sus antiguas costumbres e idiomas; pero a medida que aumentan sus relaciones con los blancos, van adaptándose rápidamente al género de vida de éstos y abandonando su lengua por la castellana [...]. (Gagini, 1917, p. 9)
}

Sin embargo, tales comentarios sobre el trasfondo del proceso de muerte de las lenguas no pasaban de ser sucintas observaciones en las que no se profundizaba. Será a partir de la década de 1980 cuando se estudiará y describirá pormenorizadamente el fenómeno, tanto en sus manifestaciones puramente lingüísticas o estructurales (la obsolescencia o "atrofia" del sistema de la lengua en los niveles fonológico, léxico, gramatical y, ya en el siglo XX, también 
el discursivo) como en su faceta sociolingüística (reducción de dominios funcionales, perfiles intergeneracionales en cuanto a la competencia lingüística, factores determinantes del proceso de desplazamiento). ${ }^{10}$

Con el trabajo pionero de Portilla-Chaves (1985, 1986), tomará fuerza el interés de los lingüistas por describir detalladamente el proceso de desplazamiento de las lenguas indocostarricenses y del inglés criollo. En general, se seguirán metodologías cuantitativas para dar cuenta de las esferas de uso y las preferencias y actitudes lingüísticas de los miembros de las comunidades estudiadas (Constenla-Umaña, 1988; Portilla-Chaves, 1985, 1986; Spence, 1997, 2001; Zimmer, 2011), o se caracterizará la vitalidad de los idiomas según los parámetros propuestos por Bauman (1980) para determinar los estados de conservación de una lengua (Castro, 2008; Constenla, 2011b; Margery-Peña, 1993; Quesada, 2008b; Quesada-Pacheco, 2008a, 2008b, 2009) o según los parámetros de la Unesco (Sánchez-Avendaño, 2013), o bien se recurrirá a datos censales sobre la vitalidad linguiística (Rojas-Chaves, 1997-1998; SánchezAvendaño, 2009). Más recientemente, se ha abordado también el estudio de las ideologías linguiísticas involucradas en el proceso de desplazamiento y se ha recurrido a metodologías cualitativas para la descripción de la situación sociolingüística (Sánchez-Avendaño, 2011).

Así, por ejemplo, en el trabajo de Portilla-Chaves $(1985,1986)$, se esboza el contexto sociohistórico que explicaría cómo se llegó a la situación de obsolescencia en el que se encontraba el térraba para la fecha de su investigación y se examinan los diversos factores concurrentes en el proceso de declinación de este idioma: falta de estandarización, traslado de los térrabas de su territorio ancestral, desequilibrio económico con respecto al grupo dominante, dominación ideológica, colonización de la zona por campesinos hispanohablantes y represión escolar, entre otros. Todos estos factores habrían coadyuvado a que la lengua viera reducidos sus dominios funcionales y a que cesara la transmisión natural:

\footnotetext{
La aculturación creciente a que se vio sometida la población indígena de Térraba contribuyó indudablemente a acrecentar las esferas de uso del español, con el consiguiente detrimento en la utilización de la lengua autóctona.

La misma posición de desventaja socioeconómica y cultural ocupada por los indios frente a los blancos en este proceso de contacto y asimilación que llevaron a cabo estos pueblos, condujo a la creación de una serie de estereotipos culturales, algunos específicamente lingüísticos, orientados a menospreciar la cultura y lengua aborígenes. (Portilla-Chaves, 1986, pp. 106-107)
}

En esta misma línea, en el también trabajo pionero de Constenla-Umaña (1988) sobre la declinación de la lengua malecu en uno de los asentamientos de este grupo, se establecerá el devenir histórico de la comunidad de hablantes y se pasará revista a los factores concurrentes: reducción demográfica, pérdida de autonomía y del hábitat tradicional, contacto prolongado y constante con hispanohablantes, declinación de la religión tradicional y de los conocimientos ancestrales, y cese del aislamiento.

Para el caso del brunca (boruca), los factores recurrentemente mencionados por diversos autores (Castro, 2008; Quesada, 2000; Quesada-Pacheco, 2008a, 2008b) son los siguientes: urbanización del territorio y establecimiento de infraestructura, represión de la escuela, actitudes desfavorables hacia la lengua vernácula, pérdida de otros componentes de la cultura tradicional, contacto estrecho con hispanohablantes. Semejantes caracterizaciones se llevan a cabo con respecto a otras lenguas, como el buglere (Quesada, 2008) y el malecu (Sánchez-Avendaño, 2011). El cuadro 1 recoge los principales factores concurrentes mencionados en las distintas publicaciones: 


\section{Cuadro 1. Factores implicados en el desplazamiento de las lenguas costarricenses según diversos investigadores}

\begin{tabular}{|c|c|c|}
\hline Factor & Lengua & Autores \\
\hline $\begin{array}{l}\text { Falta de estandarización de la lengua en un } \\
\text { contexto de competencia entre idiomas }\end{array}$ & térraba & Portilla (1986) \\
\hline \multirow{3}{*}{$\begin{array}{l}\text { Dominación o subordinación política, militar, } \\
\text { socioeconómica y cultural }\end{array}$} & térraba & Portilla (1986) \\
\hline & brunca (boruca) & Quesada Pacheco (2008b) \\
\hline & malecu (guatuso) & Constenla (1988), Sánchez (2011) \\
\hline Menor prestigio cultural y lingüístico del grupo & térraba & Portilla (1986) \\
\hline \multirow{2}{*}{ Traslado del hábitat original } & térraba & Portilla (1986) \\
\hline & buglere (bocotá) & Quesada (2008a) \\
\hline \multirow{4}{*}{$\begin{array}{l}\text { Contacto prolongado y frecuente con } \\
\text { hispanohablantes }\end{array}$} & térraba & Portilla (1986) \\
\hline & brunca (boruca) & Castro (2008) \\
\hline & malecu (guatuso) & Constenla (1988), Sánchez (2011) \\
\hline & criollo limonense & Zimmer (2011) \\
\hline \multirow{5}{*}{$\begin{array}{l}\text { Labor represiva de las escuelas y política } \\
\text { gubernamental asimilacionista }\end{array}$} & térraba & Portilla (1986) \\
\hline & brunca (boruca) & Castro (2008), Quesada (2001-2002) \\
\hline & buglere (bocotá) & Quesada (2008) \\
\hline & huetar & Quesada Pacheco (1996a) \\
\hline & criollo limonense & Zimmer (2011) \\
\hline $\begin{array}{l}\text { Actitudes desfavorables o negativas hacia la } \\
\text { lengua vernácula }\end{array}$ & brunca (boruca) & $\begin{array}{l}\text { Castro (2008), Quesada (2001- } \\
\text { 2002), Quesada Pacheco (2008b) }\end{array}$ \\
\hline \multirow{2}{*}{$\begin{array}{l}\text { Cese de la situación de aislamiento y } \\
\text { consecuente urbanización }\end{array}$} & brunca (boruca) & Castro (2008) \\
\hline & malecu (guatuso) & Constenla (1988), Sánchez (2011) \\
\hline $\begin{array}{l}\text { Introducción de infraestructura "moderna" en } \\
\text { el territorio }\end{array}$ & brunca (boruca) & Castro (2008) \\
\hline \multirow{3}{*}{$\begin{array}{l}\text { Aculturación y pérdida de componentes de la } \\
\text { cultura tradicional (vivienda, alimentación, } \\
\text { religión, medicina, etc.) }\end{array}$} & brunca (boruca) & Castro (2008) \\
\hline & buglere (bocotá) & Quesada (2008) \\
\hline & malecu (guatuso) & Constenla (1988) \\
\hline $\begin{array}{l}\text { Convivencia, prolongada y subordinada, con } \\
\text { otro grupo amerindio }\end{array}$ & buglere (bocotá) & Quesada (2008) \\
\hline \multirow{4}{*}{$\begin{array}{l}\text { Reducida demografía, descenso demográfico, } \\
\text { mestizaje, desequilibrio demográfico con } \\
\text { respecto a los hispanocostarricenses }\end{array}$} & brunca (boruca) & Quesada Pacheco (2008) \\
\hline & huetar & Quesasa Pacheco (1996) \\
\hline & malecu (guatuso) & Constenla (1988), Sánchez (2011) \\
\hline & criollo limonense & Zimmer (2011) \\
\hline
\end{tabular}

De este modo, como se puede apreciar, el segundo interés exocomunitario ha residido en intentar explicar las causas del desplazamiento y muerte de las lenguas en términos de factores principalmente socioeconómicos, históricos, demográficos, ideológico-actitudinales y de política estatal y educativa. Básicamente, se ha intentado describir el contexto amplio en el que se produce la sustitución lingüística y explicar de qué manera los diversos factores extralingüísticos específicos han confluido en el proceso de declinación de cada idioma.

Dentro de este interés por estudiar el proceso y establecer los factores concurrentes o las causas del desplazamiento se encuentra otra perspectiva, que solo aparece de modo tangencial en algunos autores (por ejemplo, en Castro, 2008 y Quesada-Pacheco, 2008b) 
y que desarrolla más ampliamente Quesada (2008): la atribución de responsabilidad a las propias comunidades etnolingüísticas por la pérdida de sus idiomas ancestrales al asignárseles "agentividad" en el proceso de sustitución. En este caso, la proposición ideológica podría enunciarse de la siguiente manera: "la lengua se pierde porque los hablantes deciden dejar de hablarla, porque no quieren conservarla o porque no desean esforzarse por mantenerla".

Así, por ejemplo, Quesada-Pacheco, al referirse al criterio de flexibilidad propuesto por Bauman (1980), afirma que los borucas "han preferido el camino más fácil, olvidar por completo su idioma” (2008b, p. 28). Del mismo modo, Castro alude a la falta de disposición de los bruncas para intentar conservar su lengua ancestral:

\footnotetext{
There seems to be a sense of shame towards the Boruca language. Situations are opposing and even contradictory sometimes. There are Boruca classes in the elementary school, and people say it is "somewhat sad" that the language is not spoken anymore, but clearly people do not appreciate the language enough to make a real effort to maintain it. (2008, p. 60)
}

Cabe destacar, eso sí, que esta visión de que la lengua vernácula no se adquiere o conserva por voluntad (es decir, intencionalmente) no se encuentra solo en los autores de la tercera época, sino que también se puede rastrear en intelectuales de otros períodos, como se aprecia en las siguientes palabras de Arroyo:

\footnotetext{
Nuestro indio diezmado y miserable, casi carente de tradición, de música propia, de arte y escaso de folklore, cada día se adapta más a la vida moderna, olvidando sus tradiciones y lenguas. Los indios jóvenes y los niños, por ejemplo, no quieren aprender su lengua materna, a la que miran hasta con vergüenza, por un complejo psicológico explicable en una raza vencida por el conquistador primero, y humillada después hasta nuestros días por abusos y arbitrariedades vergonzosas. (1966, p. 16)
}

Sin embargo, la formulación más detallada de esta perspectiva la hallamos en Quesada (2008). Este lingüista se refiere al mantenimiento y a las condiciones socio-históricas de las lenguas de la familia chibcha en general, cuyos hablantes viven desde hace siglos en una situación de asimetría social y que en el presente atraviesan por una fase crítica decisiva en cuanto a su futuro. Al respecto, propone una tipología basada en los criterios de preservación y defensa de las culturas tradicionales y las lenguas vernáculas, en la que prima la consideración o no de la lengua como factor de cohesión y mantenimiento de la cultura por parte de las comunidades de hablantes.

En lo que concierne a los idiomas de Costa Rica, cataloga como vegetantes (idiomas que se han conservado no por las medidas tomadas por sus hablantes, sino por circunstancias azarosas, como el aislamiento) al cabécar, el bribri y el nove; como obsolescentes (lenguas en las que se ha producido cese de la transmisión intergeneracional debido a diversos factores, como la reducida demografía, la migración y la integración) al buglere; y como indiferentes (los hablantes se muestran desinteresados en su conservación y puede ser que hasta experimenten vergüenza por estos) a las comunidades térraba, boruca y malecu. Ninguno de los idiomas indocostarricenses es clasificado como resistente (en cuyo caso el idioma se transmite y es empleado por las generaciones más jóvenes y es concebido como emblema identitario y como objeto de orgullo). ${ }^{11}$

\subsection{Tercer interés: Llamar a emprender acciones para la conservación y revitalización de las lenguas}

Ya desde la segunda época se puede encontrar el inicio del interés de los exocomunitarios por emprender iniciativas encaminadas a frenar el proceso de desplazamiento y a promover el uso y la revitalización de las lenguas endógenas de Costa Rica. Así lo manifiesta, al menos, Arroyo a mediados de 1960: 
En Boruca solamente los adultos y los ancianos practican su lengua. Creemos que dentro de algunos años el brunka sólo será un recuerdo de la historia, si no se hace algo por impedir su desaparición. Editar cartillas o silabarios para que los indios escolares aprendan a escribir como hablan, sería una medida eficaz y conveniente. (1966, p. 16)

Como se ve, Arroyo plantea que la pérdida de los idiomas podría evitarse con la enseñanza de la lecto-escritura, en las lenguas vernáculas, a los niños en edad escolar. Precisamente, esta idea de que la incorporación de las lenguas al currículo escolar es una medida (por no decir "la medida") adecuada para enfrentarse a la sustitución lingüística será la que preponderará en los esfuerzos llevados a cabo por los exocomunitarios.

De hecho, en Costa Rica, las iniciativas de mantenimiento y revitalización lingüística se han centrado mayoritariamente en la enseñanza de los idiomas indígenas como una asignatura escolar, sea como lengua materna o como segunda lengua. Es decir, la revitalización y conservación de estos idiomas se ha abordado con la estrategia que podría considerarse más tradicional en planificación lingüística.

Dicho programa de educación "bilingüe" en los territorios indígenas ha consistido en enseñar dos asignaturas (una de lengua vernácula y otra de cultura tradicional) e impartir las demás materias en español en el nivel de primaria. En teoría, de acuerdo con Rojas-Chaves (1997-1998), la finalidad principal que persigue dicho programa consiste en fortalecer las culturas amerindias y la identidad étnica de las personas, por medio del incentivo del conocimiento y la revaloración de las prácticas tradicionales, la historia, los conocimientos ancestrales y la relación con la naturaleza.

Otros proyectos de planificación lingüística con miras a conservar, revitalizar o alfabetizar a las poblaciones en sus respectivas lenguas vernáculas han sido los siguientes: la grafización de las lenguas y la publicación de silabarios y cartillas; la capacitación de los maestros en cuanto a las lenguas vernáculas y el arte verbal tradicional, así como en relación con su didáctica; la enseñanza de la lengua a los adultos mediante talleres mensuales y la publicación de gramáticas pedagógicas (particularmente en el caso del boruca); y la publicación de materiales didácticos para los cursos en las escuelas, muchos de ellos dirigidos a fomentar la lectura y la escritura de las lenguas. ${ }^{12}$

Como ya anotamos, algunas veces los autores de trabajos realizados dentro del marco de la lingüística descriptiva y documental han externado su esperanza de que sus publicaciones sean la simiente o sirvan de base para la revitalización de las lenguas estudiadas, especialmente en lo que concierne a la elaboración de materiales didácticos y la formación de maestros. Estos argumentos se explicitan con claridad en los siguientes extractos de la sección introductoria de dos trabajos de Constenla-Umaña, uno sobre el malecu (guatuso) y otro sobre el térraba:

\footnotetext{
Entre las distintas aplicaciones [del libro en que se describe la estructura de la lengua malecu], tiene, por supuesto, enorme interés el papel de la descripción gramatical como base para la elaboración de materiales didácticos que puedan contribuir a la retención de la lengua por parte del grupo étnico y a la preparación de las personas que participen como maestros en actividades de enseñanza bilingüe en las comunidades guatusas. (1998, p. 5)

Este trabajo [sobre el térraba] tiene como finalidad hacer disponible un tratamiento general de la fonología y la morfosintaxis, y un acervo de material léxico de la lengua [...]. Espero que sirva de estímulo para nuevos esfuerzos destinados a ampliar nuestro conocimiento sobre la lengua de Térraba y contribuya a la posibilidad de que se desarrollen programas de revitalización tendientes a devolver al pueblo térraba este y otros aspectos de su herencia cultural. (2007, pp. 6-7)
}

En el fondo, empero, si bien el interés por intervenir en los procesos de desplazamiento de los idiomas ha estado presente, este no siempre se ha concretado en acciones encaminadas 
a lograr dicho fin. En particular, con la notable excepción de los abecedarios ilustrados (Sánchez-Avendaño, 2013), quizás no se ha reflexionado lo suficiente en lo que respecta a la brecha entre las producciones de carácter académico y el requerimiento de materiales diseñados específicamente para responder a las necesidades y el contexto propio de los endocomunitarios. Es decir, no parece haber mucha conciencia - de parte de los exocomunitarios académicosen cuanto a la necesidad de idear estrategias para "filtrar" el saber especializado y producir materiales más accesibles.

En términos generales, sobre todo cuando ha primado el trabajo de descripción de las lenguas más que la aplicación y verificación de teorías, lo que más ha interesado en la labor académica ha sido el tratamiento de los datos linguiísticos y de arte verbal de forma rigurosa y científica (de acuerdo con los cánones de la lingüística descriptiva), con el fin de preservar la información sobre la estructura particular de los idiomas y los textos representativos de las respectivas culturas. Así se explicita, por ejemplo, en Castro: Since there are not many informants [of Brunca] still available to conduct linguistic research, some of
the already existing material can be of great help in analyzing and studying the language, given that it
represents the oral information that can be retrieved only partially from today's surviving semi-speakers
of the language. (2008, p. 59)

Aun así, los llamados a intervenir con iniciativas de planificación y revitalización lingüística son cada vez más comunes en el discurso exocomunitario académico:

[E]sta lengua [el buglere] está en serio peligro de extinción, al menos en Costa Rica. Eso hace necesario continuar el análisis descriptivo de la misma antes de que sea tarde; lo mismo vale para tareas de revitalización. (Quesada, 2008, p. 50)

Igualmente, es cada vez más habitual la preocupación de los académicos porque su trabajo llegue a manos de los endocomunitarios con el propósito de que entre ellos circule la información acerca de su propia lengua y se conciencien con respecto a la pérdida de su cultura, a la par que se impele a intensificar el trabajo de campo y la documentación. Es decir, ya no se incita únicamente a emprender la documentación y descripción, sino que también se considera importante acompañar estas labores con la divulgación y puesta en circulación de los datos recopilados entre los endocomunitarios, lo cual se diferencia de manera importante del interés puramente documentalista al que nos referimos en el primer subapartado. Así queda patente, por ejemplo, en dos de las propuestas de acción indicadas por Quesada-Pacheco:

\footnotetext{
Recopilar, entre los hablantes borucas, la mayor parte del material lingüístico y cultural posible, mediante intensas y frecuentes visitas a las localidades con el fin de extraer de sus hablantes y habitantes la mayor parte de rasgos culturales posible.

Dar a conocer los materiales recopilados, sea mediante publicaciones o avances de investigación, en la población aborigen, con el fin de crear conciencia y de que vean concretizados sus propios esfuerzos, sin los cuales cualquier tarea para salvaguardar el patrimonio cultural sería vana. (2008b, p. 36)
}

Sea como fuere, entonces, en la perspectiva exocomunitaria, se ha pensado que la mejor forma de revitalización y mantenimiento consiste en luchar contra el desplazamiento lingüístico por medio de las herramientas propias de la institución escolar de origen occidental, con la idea subyacente de que los idiomas normalmente se aprenden (en el caso de las segundas lenguas) o se estudian (en el caso de la lengua materna) en la escuela o por medio de cursos en los cuales se adquiere el idioma por componentes separados y en "dosis", con un énfasis importante en aspectos de la gramática y en listados de vocabulario, al mejor estilo de los programas estructurales. ${ }^{13}$ 
Sin duda alguna, esta noción de enseñanza-aprendizaje de los idiomas permea los textos que se han publicado en Costa Rica en el caso de las lenguas amerindias, sea para el estudio por parte de los endocomunitarios como por parte de los exocomunitarios (por ejemplo, en los cursos universitarios). La justificación de formular un curso estructural de base gramatical aparece explícitamente en el texto de boruca escrito por Quesada-Pacheco (1995), quien indica que los bruncas suelen concebir que el aprendizaje sistemático de su idioma vernáculo se reduce a la memorización de palabras y frases construidas, motivo por el cual se requiere un método gramatical (de hecho, el texto de Quesada se inscribiría dentro de la tradición de didáctica de segundas lenguas conocida como método de gramática-traducción, con algunos rasgos del método audiolingüe):

\footnotetext{
[E]l curso [de boruca] va dirigido a aquellas personas interesadas en adquirir destreza en el manejo de la lengua boruca, en particular a los hablantes menos y poco fluidos, con el fin de que, al final de las lecciones, sean capaces de entablar una conversación elemental en la lengua boruca. Pero también el curso está dirigido a personas que no sepan absolutamente nada de boruca. [...]

Hay una idea muy difundida entre la población, según la cual basta aprender algunos vocablos y frases de memoria para llegar a hablar la lengua. Con la presente gramática quiero combatir esa falsa idea y ofrecer a la vez un instrumento útil, donde el interesado hallará las reglas fundamentales de la estructura del idioma. (1995a, pp. 15-17)
}

Tal vez como reacción a la tendencia que podríamos llamar "tecnicista" y "gramaticalista", descrita párrafos arriba, también se ha hecho presente en los últimos años el otro extremo: la tendencia empirista de recopilar y divulgar datos sin criterio técnico lingüístico o pedagógico. El resultado ha sido la publicación de materiales variopintos, sobre todo para ayudar en la enseñanza formal de las lenguas, en los que por lo general se recogen vocabularios sin ninguna sistematicidad y sin claridad en cuanto a los objetivos didácticos, o se reúnen textos del arte verbal tradicional transcritos muchas veces con una ortografía asistemática, sin traducción especializada y sin tratamiento didáctico. Frecuentemente esta labor la han llevado a cabo -sin duda con las mejores intenciones-individuos e instituciones exocomunitarias, muchas veces en conjunto con endocomunitarios. ${ }^{14}$

En todo caso, dejando de lado la evaluación de la calidad "técnica" de los materiales, debe reconocerse que existe una preocupación creciente por producir textos que sirvan de base para las clases de lengua y cultura en las comunidades indígenas, como se indica en el prólogo a la serie de textos $S a$ ñayuwä sa siwawa. Estudiemos cabécar:

\footnotetext{
La presente serie de textos nace a partir de la necesidad de sistematizar los conocimientos de la cultura cabécar, en un material educativo para las nuevas generaciones [...]. La labor de trasladar el conocimiento de la cultura oral a la escrita, se ha hecho con el deseo de aportar un material didáctico para la enseñanza en las escuelas con niños cabécares, con el fin de que lleguen a dominar tanto el español como la lectoescritura de su lengua materna. [...]

Dado que no existe una pedagogía oficial, este material se plantea como el primer intento para la construcción de una base que facilite la enseñanza del cabécar. (Hedström-Rojas y Martínez-Sanabria, 2005, p. 7)
}

Finalmente, cabe resaltar que, al lado de este interés por emprender acciones de revitalización, los autores también destacan el peso de las comunidades en el éxito de cualquier iniciativa al respecto:

Para finalizar, quisiera subrayar que ningún empeño de revitalización lingüística podrá cumplirse sin la voluntad y el deseo de la población afectada. Por consiguiente, depende en gran parte de los borucas la preservación de su patrimonio lingüístico y el éxito de cualquier iniciativa que vaya en esta dirección. (Quesada-Pacheco, 1995, pp. 15-17) 


\section{Conclusiones}

En Costa Rica, la perspectiva con la que los individuos externos a las comunidades con idioma propio distinto al español han asumido y se han enfrentado al fenómeno de la muerte de lenguas y las lenguas en peligro no difiere, en esencia, de la que se puede hallar en otros países. No obstante, hay que recalcar que el interés por estos temas no es reciente, sino que data al menos de la segunda mitad del siglo XIX.

Asimismo, se puede apreciar una evolución en el pensamiento y algunas constantes. En primera instancia, el interés documentalista y descriptivo, el primero en aparecer en la historia del tratamiento académico de los idiomas de Costa Rica, seguirá vigente hasta nuestros días y producirá una ingente cantidad de publicaciones, en un inicio realizadas por lingüistas aficionados, y luego llevadas a cabo de modo profesional y con base en teorías y metodologías asentadas. Paulatinamente, este interés se verá acompañado por el reconocimiento de la necesidad de emprender iniciativas de conservación y revitalización lingüística.

El interés por dar cuenta de los procesos y causas del desplazamiento o de la conservación de los idiomas también aparecerá, aunque de modo marginal y vago, desde los primeros trabajos, pero se profesionalizará a partir de la década de 1980, cuando el tema será tratado desde marcos teóricos particulares para tal propósito y se describirán pormenorizadamente los factores concurrentes en la sustitución lingüística y el devenir sociolingüístico de algunos pueblos.

Por último, cabe destacar que, aparte de algunas alusiones muy generales, no aparece con explicitud en los discursos de los exocomunitarios la tesis de que la extinción de las lenguas implica pérdida del patrimonio cultural de la humanidad, de conocimientos milenarios acerca de la relación con la naturaleza y de claves para comprender los intrincados mecanismos del desarrollo cognitivo humano, como sí ocurre en el discurso de académicos de otros países (v.g. Harrison, 2007; Evans, 2010). Como excepción, se pueden citar los siguientes dos extractos, en los que se establecen vínculos variados - pero sin mayor detalle- entre lengua, identidad y visión de mundo, y entre lengua y codificación/expresión de la experiencia:

\footnotetext{
La lengua cabécar, al igual que todas las lenguas, constituye una forma de entender el mundo y de ser; es una manifestación de la identidad indígena. (Hedström-Rojas y Martínez-Sanabria, 2005, p. 7)

Cada lengua es el vehículo más adecuado para la expresión de la particular experiencia de la condición humana obtenida por el pueblo que la habla a lo largo de su trayectoria histórica. Lógicamente, quienes hemos tenido la suerte de poder apreciar los enormes valores de las culturas autóctonas aspiramos a que estos y las lenguas más apropiadas para comunicarlos no solo se conserven, sino que se robustezcan. Por otra parte, como lingüista opino que en cada lengua se encierran aclaraciones indispensables para el conocimiento del objeto de nuestra disciplina: el lenguaje. (Constenla-Umaña, Elizondo-Figueroa, Pereira-Mora, 1998, p. vii)
}

\section{Notas}

1. Deseo expresarle mi agradecimiento a Ronald Hernández Campos y a Diego Ugalde por la revisión minuciosa del texto y sus sugerencias. Asimismo, deseo dejar constancia de la invaluable ayuda del M.L. Henry Angulo con la traducción del resumen al inglés.

2. Lo habitual ha sido referirse a este idioma en español con el acrónimo LESCO o con la frase "lenguaje de señas costarricense". Más recientemente, se ha insistido en emplear la denominación "lengua de señas costarricense", con el fin de sustituir la etiqueta "lenguaje" por el de "lengua" y así luchar contra el prejuicio de considerar las lenguas de señas como algo distinto a un idioma. Como resultado, también se ha cambiado el género del acrónimo, de modo que se promueve la forma "la LESCO" en lugar de "el LESCO". Coincidimos con esta posición en lo que respecta a la necesidad de emplear la denominación "lengua" y no "lenguaje", pero creemos que es hora de empezar a escribir el nombre de la lengua en minúscula, pues, si bien se trata de un acrónimo en origen, se usa en la actualidad como cualquier otro 
glotónimo en español. Asimismo, preferimos usar el género masculino, por la simple razón de que los nombres de los idiomas en español son todos masculinos. Por este motivo, escribimos "el lesco" o "la lengua de señas costarricense", al igual que escribimos, por ejemplo, "el bribri" o "la lengua bribri".

3. Cabe destacar que, en lo que respecta a los textos académicos, no incluimos la referencia bibliográfica de aquellos caracterizados por no explicitar el motivo de su publicación. Esto es, no consignamos la referencia de los textos que omiten aludir al tema que nos ocupa en el presente artículo, por cuanto ello demandaría más espacio del que disponemos. El listado "exhaustivo" de publicaciones revisadas en las que se basa el presente análisis y la síntesis o generalización en cuanto al proceder se puede encontrar en Sánchez-Avendaño (2013).

4. Conservamos la ortografía original de todos los textos citados.

5. Consignamos la traducción publicada en Fernández (1883) en lugar del original en inglés (Gabb, 1875).

6. Por este motivo, por ejemplo, los términos de parentesco se incluyen en los listados léxicos como equivalentes absolutos, como si la organización semántico-cultural de estos sistemas y su expresión lingüística fueran universales Así, Thiel (1882) consigna términos de parentesco en malecu como traducciones exactas de las palabras en castellano (v.g. abuela-nachíya; abuelo-na chái yu; primo hermano (mío)-fóroja, tona fóroja; suegra-fafára; tía-fruca ora; yerno-tóna fúeh) y registra traducciones para conceptos desconocidos en la cultura malecu de fines del siglo XIX (v.g. iglesia-tocu uh, literalmente 'casa de dios').

7. Según Haviland, este interés muchas veces ha conllevado el propósito de emplear los productos lexicográficos como instrumentos de ayuda para la conversión religiosa y el control. En nuestra opinión, sin embargo, este no parece ser el caso de los glosarios recogidos en Costa Rica durante este período.

8. Ver al respecto Sánchez Avendaño (2013).

9. Consignamos la traducción de Quesada Pacheco (2001) del original en alemán (Pittier, 1904, p. 707).

10. No se debe olvidar, empero, que, desde muchos años antes, algunos antropólogos habían publicado estudios detallados sobre la situación de aculturación de varios grupos, lo que incluía referencias a la pérdida de sus idiomas vernáculos (Stone, 1949, 1961; Bozzoli, 1969).

11. Es muy posible que esta tipología no pretenda, en el fondo, culpabilizar a las comunidades o a los hablantes. De hecho, el autor termina su artículo con la consideración de si el papel de los lingüistas debería ser "intentar levantar la autoestima étnica" en las situaciones de indiferencia, por estar esta actitud motivada por problemas con el orgullo por el origen. No obstante, es de reprochar la asignación tan directa de agentividad en un proceso tan complejo como el de la sustitución lingüística, en el que está a la orden del día la contradicción entre la realidad sociocomunicativa frente a lo expresado como deseable o ideal por los propios comunitarios, y en el que suelen preponderar los factores extralingüísticos de tipo puramente histórico-social, resultantes de la pérdida de autonomía y control del hábitat ancestral, así como los de índole económica, como la inserción abrupta del grupo a la economía de mercado en condiciones de desigualdad de oportunidades y manejo de recursos.

12. Véase Sánchez Avendaño (2013) para referencias bibliográficas al respecto.

13. Como explica Ellis (1997), en tales programas se enseñan rubros gramaticales (y habría que agregar también el léxico) en orden y gradualmente, pues se concibe el proceso de adquisición como una acumulación gradual de las partes de la lengua hasta que se llega a construir la totalidad del sistema. Además, al aprendiz se le deja esta labor de síntesis de las partes que se han presentado como piezas, suponiendo que este será capaz de armar un discurso cohesionado y coherente por sí mismo a partir de lo aprendido en partes.

14. Ver Sánchez Avendaño (2013) para una bibliografía relativamente exhaustiva al respecto.

\section{Bibliografía}

Arroyo-[Soto], V.M. (1966). Lenguas Indígenas Costarricenses. San José: Editorial Costa Rica.

Bauman, J.J. (1980). A Guide to Issues in Indian Language Retention. Washington: Center for Applied Linguistics. 
Boza-Villarreal, A. (2005). La población indígena de la Gran Talamanca: tamaño y ubicación. Costa Rica, 1840-1927. Revista Historia. 51-52, 9-78.

Bozzoli de Wille, M.E. (1969). Localidades indígenas costarricenses. San José: EDUCA.

Bozzoli de Wille, M.E. (1986). El indígena costarricense y su ambiente natural: Usos y adaptaciones. San José: Editorial Porvenir.

Cameron, D. (2007). Language endangerment and verbal higiene: History, morality and politics. Por A. Duchêne y M. Heller (Eds.). Discourses of Endangerment. Ideology and Interests in the Defense of Languages. (268-285). Londres: Continuum.

Castro, D. (2008). Brúnkahk Tek: An Extinct Language. Letras. 43, 51-74.

Colón-Domènech, G. y Gimeno-Betí, L. (Eds.). (2007). Ecologia lingüística i desaparició de llengües. Castelló de la Plana: Publicacions de la Universitat Jaume I.

Constenla-Umaña, A. (1975). La lengua guatusa: fonología, gramática y léxico. (Tesis de licenciatura). Universidad de Costa Rica.

Constenla-Umaña, A. (1984). El huetar: observaciones sobre los materiales disponibles para su estudio y sobre las hipótesis en torno a sus afinidades lingüísticas. Revista de Filología y Lingüística de la Universidad de Costa Rica. 10 (2), 3-18.

Constenla-Umaña, A. (1988). El guatuso de Palenque Margarita: su proceso de declinación. Estudios de Lingüística Chibcha. 7, 7-37.

Constenla-Umaña, A. (1994). Las lenguas de la Gran Nicoya. Vínculos. $18-19$ (1-2), 191-208.

Constenla-Umaña, A. (2004). El estudio de las lenguas de la Baja Centroamérica desde el siglo XVI hasta el presente. Estudios de Lingüística Chibcha. 23, 9-58.

Constenla-Umaña, A. (2007). La lengua de Térraba. San José: Editorial de la Universidad de Costa Rica.

Constenla-Umaña, A. (2011a). La diversidad lingüística de Costa Rica: Las lenguas indígenas. Revista de Filología y Lingüística. 37 (2), 93-106.

Constenla-Umaña, A. (2011b). Estado de conservación y documentación de las lenguas de América Central pertenecientes a las agrupaciones jicaque, lenca, misumalpa, chibchense y chocó. Revista de Filología y Lingüística. 37 (1), 135-195.

Constenla-Umaña, A. y Maroto, E.S. (1979). Leyendas y tradiciones borucas. San José: Editorial de la Universidad de Costa Rica.

Constenla-Umaña, A., Castro, E. y Blanco, A. (1993). Laca Majifijica. La transformación de la tierra. San José: Editorial de la Universidad de Costa Rica.

Constenla-Umaña, A., Elizondo-Figueroa, F. y Pereira-Mora, F. (1998). Curso básico de bribri. San José: Editorial de la Universidad de Costa Rica.

Constenla-Umaña, A. y Ibarra-Rojas, E. (2009). Mapa de la distribución territorial aproximada de las lenguas indígenas habladas en Costa Rica y en sectores colindantes de Nicaragua y Panamá en el siglo XVI. Estudios de Lingüística Chibcha. 28, 109-112.

Duchêne, A. y Heller, M. (Eds.). (2007). Discourses of Endangerment. Ideology and Interests in the Defense of Languages. Londres: Continuum. 
Ellis, R. (1997). SLA Research and Language Teaching. Oxford: Oxford University Press.

Evans, N. (2010). Dying Words. Endangered Languages and What They Have To Tell Us. Oxford: Wiley-Blackwell.

Fernández, L. (1883). Colección de documentos para la Historia de Costa Rica. (Vol. 3). San José: Imprenta Nacional.

FUNCOOPA. (1997). Los pueblos indígenas de Costa Rica. Historia y situación actual. San José: FUNCOOPA.

Gabb, W.M. (1875). On the Indian tribes and languages of Costa Rica. Washington: Sthmisonian Museum.

Gabb, W.M. (1883). Tribus y lenguas indígenas de Costa Rica. Por L. Fernández. Colección de documentos para la Historia de Costa Rica. (303-486). San José: Imprenta Nacional.

Gagini, C. (1917). Los aborígenes de Costa Rica. San José: Imprenta Trejos Hermanos.

Gippert, J., Himmelmann, N. y Mosel, U. (2006). Essentials of Language Documentation. Berlín: Mouton de Gruyter.

Grinevald, C. y Bert, M. (2010). Faits de langues. Linguistique de terrain sur langues en danger. Locuteurs et linguistes. París: Ophrys.

Grinevald, C. y Costa, J. (2010). Langues en danger: le phénomène et la réponse des linguistes. Por C. Grinevald y M. Bert (Eds.). Faits de langues. Linguistique de terrain sur langues en danger. Locuteurs et linguistes. (23-37). París: Ophrys.

Guevara-Berger, M. y Chacón-Castro, R. (1992). Territorios indios en Costa Rica: Orígenes, situación actual y perspectivas. San José: García Hermanos.

Guevara-Berger, M. y Bozzoli-Vargas, M.A. (2002). Los indígenas costarricenses en el siglo XXI: algunas perspectivas para la acción. San José: Editorial de la Universidad Estatal a Distancia.

Harrison, K.D. (2007). When Languages Die. The Extinction of the World's Languages and the Erosion of Human Knowledge. Nueva York: Oxford University Press.

Haviland, J. (2006). Documenting lexical knowledge. Por J. Gippert, N. Himmelmann y U. Mosel (Eds.). Essentials of Language Documentation. (129-162). Berlín: Mouton de Gruyter.

Hedström-Rojas, M. y Martínez-Sanabria, O. (2005). Sa ñayuwä sa siwawwa. Estudiemos cabécar 1. San José: Fundación Nairi.

Heller, M. y Duchêne, A. (2007). Discourses of endangerment: Sociolinguistics, globalization and social order. Por A. Duchêne y M. Heller (Eds.). Discourses of Endangerment. Ideology and Interests in the Defense of Languages. (1-13). Londres: Continuum.

Herranz, A., Barahona, M. y Rivas, R. (Eds.). (1995). Educación Bilingüe e Intercultural en Centroamérica y México. Tegucigalpa: Editorial Guaymuras.

Herzfeld, A. (2002). Mekaytelyuw: La lengua criolla. San José: Editorial de la Universidad de Costa Rica. 
Herzfeld, A. (2011). Una evaluación de la vitalidad lingüística del inglés criollo de Limón: su vigencia o su desplazamiento. Revista de Filología y Lingüística. 37 (2), 107-131.

Ibarra-Rojas, E. (1990). Las sociedades cacicales de Costa Rica (Siglo XVI). San José: Editorial de la Universidad de Costa Rica.

Jara-Murillo, C. (1993). I ttè. Historias bribris. San José: Editorial de la Universidad de Costa Rica.

Junyent, M.C. (2007). Aspectes universals i particulars dels processos de substitució lingüística. Por G. Colón-Domènech y L. Gimeno-Betí (Eds.). Ecologia lingüística i desaparició de llengües. (53-63). Castelló de la Plana: Publicacions de la Universitat Jaume I.

Lehmann, W. (1920). Zentral-Amerika. Teil I. Die Sprachen Zentral-Amerikas. Band I. Berlín: Verland Dietrich Reimer.

Laurencich, L. (1974). Un grupo de indios guaymíes en Costa Rica. América Indígena. 34 (2), 369-380.

Margery-Peña, E. (1993). Estados de conservación de las lenguas indígenas de Costa Rica frente al español. Por V. Sánchez-Corrales (Ed.). Memoria del IV Congreso Costarricense de Filología, Lingüística y Literatura. (257-266). San José: Oficina de Publicaciones de la Universidad de Costa Rica.

Martinet, A. (1962). A Functional View of Language. Oxford: The Clarendon Press.

Mercier, P. (1976). Historia de la antropología. Barcelona: Ediciones Península.

Molina-Jiménez, I. (2008). Costarricense por dicha. Identidad nacional y cambio cultural en Costa Rica durante los siglos XIX y XX. San José: Editorial de la Universidad de Costa Rica.

Murillo-Miranda, J. (2008). Notas sobre la lengua guaymí en Costa Rica. Letras. 43, 75-90.

Nieto, A. (2009, 27 de mayo). Nueve lenguas de Costa Rica están en peligro de extinción. La Nación. http://wvw.nacion.com/

Palacios-[Alcaine], A. (Coord.). (2008). El español en América. Contactos lingüísticos en Hispanoamérica. Barcelona: Ariel.

Palmisano, A. (Ed.). (2008). Identità delle comunità indigene del Centro America. Roma: IILA.

Pittier, H. (1897). Primera contribución para el estudio de las Razas indígenas de Costa Rica. San José: Tipografía Nacional.

Pittier, H. (1898). Die Sprache der Bribri-Indianer in Costa Rica. Wien: Kais. Akademie der Wissenschaften.

Pittier, H. (1904). Numeral Systems of the Costa Rican Indians. American Anthropologists. 6 (4), 447-458.

Pittier, H. (1938). Apuntaciones etnológicas sobre los indios bribris. San José: Imprenta Nacional.

Pittier, H. (1941). Materiales para el estudio de la Lengua Brunka hablada en Boruca recogidos en los años de 1892 a 1896. San José: Museo Nacional. 
Pittier, H. y Gagini C. (1892). Ensayo lexicográfico sobre la lengua de Térraba. San José: Tipografía Nacional.

Porras-Ledesma, Á. (1959). El idioma guatuso: fonética y lexicología. (Tesis de licenciatura). Universidad de Costa Rica.

Portilla-Chaves, M. (1985). Un caso de muerte de lenguas: el térraba. (Tesis de maestría). Universidad de Costa Rica.

Portilla-Chaves, M. (1986). Un caso de muerte de lenguas: el térraba. Estudios de Lingüística Chibcha. 5, 97- 246.

Quesada, J.D. (2000). Synopsis of a Boruca terminal speaker. Amerindia. 25, 65-86.

Quesada, J.D. (2001-2002). Adiós boruca: Sibú ki ba wí?ra moréng... Estudios de Lingüística Chibcha. 20-21, 55-64.

Quesada, J.D. (2008a). El buglere: lengua obsolescente. Letras. 43, 39-50.

Quesada, J.D. (2008b). Las lenguas chibchas y sus hablantes: resistencia, obsolescencia e indiferencia. Por A. Palmisano (Ed.). Identità delle comunità indigene del Centro America. (183-194). Roma: IILA.

Quesada-Pacheco, M.A. (1995a). Hablemos boruca (Chá ding di' tégat tegrá). San José: Ministerio de Educación Pública.

Quesada-Pacheco, M.A. (1995b). Revitalización de las lenguas indígenas de Costa Rica: el caso del boruca. En A. Herranz, M. Barahona y R. Rivas (Eds.). Educación Bilingüe e Intercultural en Centroamérica y México. (101-128). Tegucigalpa: Editorial Guaymuras.

Quesada-Pacheco, M.A. (1996a). Los huetares: historia, lengua, etnografía y tradición oral. Cartago: Editorial Tecnológica de Costa Rica.

Quesada-Pacheco, M.A. (1996b). Shán̈ rójc brún̈cajc rójc. Narraciones borucas. San José: Editorial de la Universidad de Costa Rica.

Quesada-Pacheco, M.A. (1999-2000). Situación actual y futuro de las lenguas indígenas de Costa Rica. Estudios de Lingüística Chibcha. 18-19, 7-34.

Quesada-Pacheco, M.A. (2001). Entre silladas y rejoyas. Viajeros por Costa Rica de 1850 a 1950. Cartago: Editorial Tecnológica de Costa Rica.

Quesada-Pacheco, M.A. (2006). Toponimia indígena de Costa Rica. Revista de Filología y Lingüística. 32 (2), 203-259.

Quesada-Pacheco, M.A. (2008a). América Central. En: A. Palacios-Alcaine (Coord.). El español en América. Contactos lingüísticos en Hispanoamérica. (57-75). Barcelona: Ariel.

Quesada-Pacheco, M.A. (2008b). Las lenguas ístmicas: entre obsolescencia y resistencia. Letras. 43, 23-37.

Quesada-Pacheco, M.A. (2009). El panteón lingüístico chibcha y sus vecinos. Letras. 45, 11-24.

Quirós-Rodríguez, J.S. (1987). Términos chorotegas en la toponimia guanacasteca. Letras. 15-16-17, 161-170.

Quirós-Rodríguez, J.S. (2002). Diccionario español-chorotega/chorotega-español. San José: Editorial de la Universidad de Costa Rica. 
Retana-Castro, P. (2011). Aproximación a la lengua de señas costarricense (LESCO). Revista de Filología y Lingüística. 37 (2), 137-146.

Rojas-Chaves, C. (1997-1998). Revitalización lingüística de las lenguas indígenas de Costa Rica. Estudios de Lingüística Chibcha. 16, 9-17.

Sánchez-Avendaño, C. (2009). Situación sociolingüística de las lenguas minoritarias de Costa Rica y Censos Nacionales de Población 1927-2000: Vitalidad, desplazamiento y autoafiliación etnolingüística. Revista de Filología y Lingüística. 35 (2), 233-273.

Sánchez-Avendaño, C. (2011). El desplazamiento de la lengua guatusa en contacto con el español: Identidad étnica, ideologías lingüísticas y perspectivas de conservación. (Tesis doctoral). Universidad Autónoma de Madrid.

Sánchez-Avendaño, C. (2013). Lenguas en peligro en Costa Rica: Vitalidad, documentación y descripción. Káñina. 37 (1), 219-250.

Sánchez-Corrales, V. (Ed.). (1993). Memoria del IV Congreso Costarricense de Filología, Lingüística y Literatura. San José: Oficina de Publicaciones de la Universidad de Costa Rica.

Spence, M. (1997). A case study of language shift in progress in Port Limon, Costa Rica. Revista de Filología y Lingüística. 23 (1), 225-234.

Spence, M. (2001). Sex, Occupation, Language Choice. The Case of the Limon Creole Speech Community. Káñina. 25 (1), 49-54.

Stone, D. (1949). The Boruca of Costa Rica. Massachussets: Peabody Museum of American Archaelogy and Ethnology.

Stone, D. (1961). Las tribus talamanqueñas de Costa Rica. San José: Museo Nacional de Costa Rica.

Thiel, B.A. (1882). Apuntes lexicográficos de las lenguas y dialectos de los indios de Costa Rica. San José: Imprenta Nacional.

Umaña-Aguiar, J. (1991). Cambio de código en Puerto Limón, Costa Rica. Káñina. 15 (1-2), 199-202.

von Frantzius, A. (1925a). Sobre los aborígenes de Costa Rica. Revista de Costa Rica. 6 (10), 218-220.

von Frantzius, A. (1925b). Sobre los aborígenes de Costa Rica. Revista de Costa Rica. 6 (11), 225-234.

Winkler, E.G. (2000). Cambio de códigos en el criollo limonense. Revista de Filología y Lingüística. 26 (1), 189-196.

Woodward, J. (1991). Sign Language Varieties in Costa Rica. Sign Language Studies. 73, 329-346.

Woodward, J. (1992). Historical Bases of New Costa Rican Sign Language. Revista de Filología y Lingüística. 18 (1), 127-132.

Zimmer, T. (2011). El español hablado por los afrocostarricenses. Estudio lingüístico y sociolingüístico. (Tesis doctoral). Universidad de Colonia. 